\title{
Collaboration, collation, and competition: Crowdsourcing a directory of educational technology tools for teaching and learning
}

\author{
Enda Donlon \\ Institute of Education, Dublin City University
}

\author{
Eamon Costello, Mark Brown \\ National Institute for Digital Learning, Dublin City University
}

\begin{abstract}
This paper reports on a distinctive one-year online open crowdsourcing initiative which originated in the Republic of Ireland with a view to compiling an A-Z directory of educational technology tools for teaching and learning. Through analysis of multiple sources of data, the paper presents an intrinsic case study which outlines the design and implementation of the initiative and offers critical insights into engagement and participation in the project. The study found that participants from across the spectrum of educational sectors contributed to this project from a range of geographical locations, with significantly greater numbers engaging with the directory of educational technology tools that resulted from the crowdsourcing activity. It concludes that the creative project design, combined with a novel crowdsourcing methodology encompassing elements of collaboration, competition, and gamification, were strong motivational factors for participation. The case study provides a valuable context for considering the wider potential of this particular crowdsourcing format (and crowdsourcing applications in general) for teaching and learning purposes.
\end{abstract}

Implications for practice or policy:

- In-depth description and analysis of the project structure and crowdsourcing methodology used within this study will be of interest to educationalists who may wish to adopt or adapt this particular crowdsourcing model.

- Practitioners who are interested in utilising crowdsourcing can increase participant engagement through encompassing elements of competition and gamification.

Keywords: crowdsourcing, edtech, motivation, engagement, collaboration, competition, case study

\section{Introduction}

The term crowdsourcing is generally attributed to Howe (2006), who described it as taking a function once performed by employees of a company or institution and using an open call to outsource this to an undefined and potentially sizeable network of people. In her consideration of contemporary applications and potentials of crowdsourcing, Foulger argued that "this technique of innovation has had huge success in business and industry, but has yet to show impact in education in great ways" (2014, p. 110). Mindful of this observation and with a view to contributing to a growing knowledge base with regard to crowdsourcing in education, this study investigated a distinctive one-year initiative designed to compile through crowdsourcing principles an A-Z directory of educational technology (edtech) tools for teaching and learning. The study was undertaken in order to learn more about the engagement that occurred with the crowdsourcing initiative and the factors that motivated people to contribute to the project. In doing so it is envisaged that insights gained from this particular project can contribute to evolving discussions regarding the practices and potentials of crowdsourcing for teaching and learning.

The paper opens with an exploration of crowdsourcing in general before proceeding to consider the application of crowdsourcing more specifically for educational purposes. The crowdsourcing initiative at the centre of this study is then outlined in detail, followed by an account of the intrinsic case study research design utilised for the investigation. Drawing on data obtained from a number of sources that includes an online survey and data from the crowdsourcing project website, the paper then considers the levels and kinds of engagement that took place with the project, the factors that motivated contributors to participate, 
and the crowdsourcing methodology formulated for the project. The paper concludes with a number of recommendations and considerations with regard to the wider lessons that can be learned from this case study.

\section{Crowdsourcing}

Howe's (2006) definition of crowdsourcing as the act of a company or institution taking a function once performed by employees and outsourcing it to an undefined (and generally large) network of people in the form of an open call is perhaps the best-known and most recognisable definition for this term. It entails the use of the open call format coupled with a large network of potential labourers with regard to the crowdsourcing focus. Estellés-Arolas and González-Ladrón-de-Guevara (2012), however, compared over 40 definitions for the term and proposed eight attributes common to any crowdsourcing initiative: the crowd with the task at hand, the recompense obtained, the crowdsourcer or initiator of the crowdsourcing activity, what is obtained by them following the crowdsourcing process, the type of process, the call to participate, and the medium. Although the term has gained much prominence since Howe's definition, Hossain and Kauranen (2015) have illustrated that many of the aforementioned features can be found in collaborative initiatives that predate Howe's work by some time, such as the use of a crowdsourcing process in 1884 by the Oxford English Dictionary to catalogue words through a crowd of 800 readers.

In terms of more contemporary applications of crowdsourcing, a number of studies have considered the issue of participant motivation, with many (such as Zhao \& Zhu, 2014) drawing an important distinction between intrinsic and extrinsic motivational factors. This distinction is evident, for instance, in a study of motivations for partaking in a crowdsourced traffic law reform, where Aitamurto, Landemore, and Saldivar Galli (2017) found that the crowd was motivated by a mix of intrinsic factors (performed for its own sake, in the pursuit of internal goals and aligned with a person's values, principles, and desires) and extrinsic factors ("oriented toward goals and rewards toward which the self has a more instrumental, external relationship, such as money or other goods") (p. 1242). Brabham's (2010) study of participants' motivations at the Threadless company also found a mix of intrinsic and extrinsic motivations for crowdsourcing, which included opportunities to make money and to develop one's creative skills, the potential to leverage freelance design work, and the love of the crowdsourcing community. In a similar vein, Karataev and Zadorozhny (2017) identified the desires to teach and contribute, community identification, and social contact as motivational factors for engaging in crowdsourcing.

It is widely acknowledged that advances in Internet technologies have made crowdsourcing practicable for greater numbers of people, products, and services, at larger scale and at significantly enhanced speed (Saxton, Oh, \& Kishore, 2013). Hossain and Kauranen (2015) identified a number of applications of crowdsourcing, including idea generation (whereby crowds are called upon to submit new ideas), microtasking (whereby users can select and complete small tasks), and citizen science (whereby the participation of crowds is utilised in solving real-world problems through a form of collaborative research). Within clinical research it has been argued that crowdsourcing can facilitate recruiting larger, more diverse patient populations, as well as enabling patients to provide research data from any location and any time (Armstrong, Cheeney, Wu, Harskamp, \& Schupp, 2012). Crowdsourcing has found application in the discipline of law to achieve legal reform and innovation in the United States and beyond (Orozco, 2016), and within the publishing industry (Mustafa \& Mohd Adnan, 2017) by authors to crowdfund through fundraising platforms in order to publish their work and by publishers to utilise readers for quality and market testing.

\section{Crowdsourcing and education}

With such widespread application evident across a range of disciplines, it is not surprising that crowdsourcing is enjoying increased uptake for educational purposes (Skaržauskaitè, 2012). The collaborative nature of crowdsourcing, which usually results in the generation of new content and knowledge, has seen it aligned with constructivist (Hills, 2015; Zahirović Suhonjić, Despotović-Zrakić, Labus, Bogdanović, \& Barać, 2019) and connectivist (Paulin \& Haythornthwaite, 2016; Zhou et al., 2018) theories of learning, which have particular resonance with regard to the potentials of digital technologies for facilitating collaboration and learning (Foroughi, 2015). In addition, the open nature of crowdsourcing naturally finds it situated within discussions regarding openness in education (Al-Jumeily, Hussain, Alghamdi, Dobbins, \& Lunn, 2015; Weller, 2011). In their review of the uses of crowdsourcing in higher 
education, Solemon, Ariffin, Din, and Anwar (2013) categorised four primary crowdsourcing strategies that can be identified within education: crowd wisdom (sharing of knowledge and gathering ideas from the crowd to solve problems or predict future outcomes), crowd creation (utilising crowdsourcing to co-create a product or service), crowd funding (where people network and pool money through small contributions and parties to accumulate funding for education projects), and crowd voting (the sourcing of opinions, ideas and decisions of the public through voting processes). These broad crowdsourcing strategies are evident in a number of applied uses of crowdsourcing within education. Within the field of medical education, for instance, Blackwell, Travis, Arbuckle, and Ross (2016) employed crowdsourcing to create and disseminate resources among teachers and found that crowdsourcing provides a "creative and effective approach to collaboratively develop shared curriculum resources" (p. 576), while Chan, Thoma, and Lin (2015) employed a similar methodology to crowdsource solutions to problem-based medical education cases in order to create and share electronic teaching resources. Crowdsourcing has also proven effective in soliciting and compiling content from teaching staff in the fields of information literacy (White-Farnham \& Caffrey Gardner, 2014), the humanities (Dunn \& Hedges, 2013), and in science, technology, education, and maths (Porcello \& Hsi, 2013). It has also been used for the collaborative creation of rich e-learning content (Tarasowa, Khalili, \& Auer, 2015) and in the compilation of open textbooks (Jhangiani, Green, \& Belshaw, 2016).

Crowdsourcing has also been utilised as a pedagogical strategy to promote student-centred learning. Hills (2015), for instance, outlined the use of crowdsourcing as an educational methodology to locate and share existing content, and to create new content, among student participants, while Zahirović Suhonjić et al. (2019) found that using a learner-centred approach through crowdsourced content creation improved both the processes and outcomes of learning in a higher education e-business course. Pionke's (2013) use of crowdsourcing to compile a collaborative bibliography among graduate students taking a seminar on Victorian literature found that "the crowdsourced digital format resulted in an exponential increase of scholarly efficiency" (p. 14). It reduced duplication of effort and entry than had been noted when students compiled individual bibliographies and also contributed to a significantly larger end product. Elsewhere, van Haren (2017) proposed that crowdsourcing can be used by students to obtain feedback on writing tasks and learn from each other, while O'Shea and Kidd (2011) considered the use of a "crowdsourced grading" model in an undergraduate course where students authored their own textbook and reviewed each other's work. In another case of student-generated content, Bow, Dattilo, Jonas, and Lehmann employed a crowdsourcing methodology to enable medical students "to share in the effort of generating concise, highyield study materials" (2013, p. 766) in compiling a database of over 16,000 study questions.

We can see, therefore, that crowdsourcing has found much favour both beyond (Hossain \& Kauranen, 2015) and within (Skaržauskaite, 2012) the realm of education, with developments in online technologies contributing significantly to the growth of this approach (Saxton et al., 2013; Solemon et al., 2013). Set against this backdrop of promise and potentials for crowdsourcing, we now turn our attention to the exploration of an online crowdsourcing project which originated in the Republic of Ireland.

\section{Project 252}

Project 252 (http://project252.donenda.com) was a year-long open crowdsourcing initiative which was undertaken to collaboratively compile an A-Z directory of edtech tools for teaching and learning (Donlon, Brown, \& Costello, 2016). The crowdsourcing project ran for the entirety of one calendar year (January 2015 to January 2016), although the project website remains active and the crowdsourced directory available (see Figure 1). It was implemented around a chronological and sequential model of design: every 2 weeks for the 52 weeks of the year (hence 252) the project focused on one letter of the alphabet, starting with A and going through to Z. For the 2 weeks of the featured letter, an open call was issued, which invited contributors to submit the details of an edtech tool (e.g., an app, Web 2.0 service or software package) with a name beginning with that letter. The rationale for this particular crowdsourcing methodology was that we considered there to be a tidy symmetry to the structure: because there are 26 letters in the alphabet, and 52 weeks in the year, this gives rise to a natural structure that sees each letter featured for 2 weeks, with all 26 letters receiving equal attention and the entire alphabet being covered in one exact calendar year. We theorised that this structure might appeal to potential contributors, and also that it might be easy to remember for those who wished to contribute regularly. 


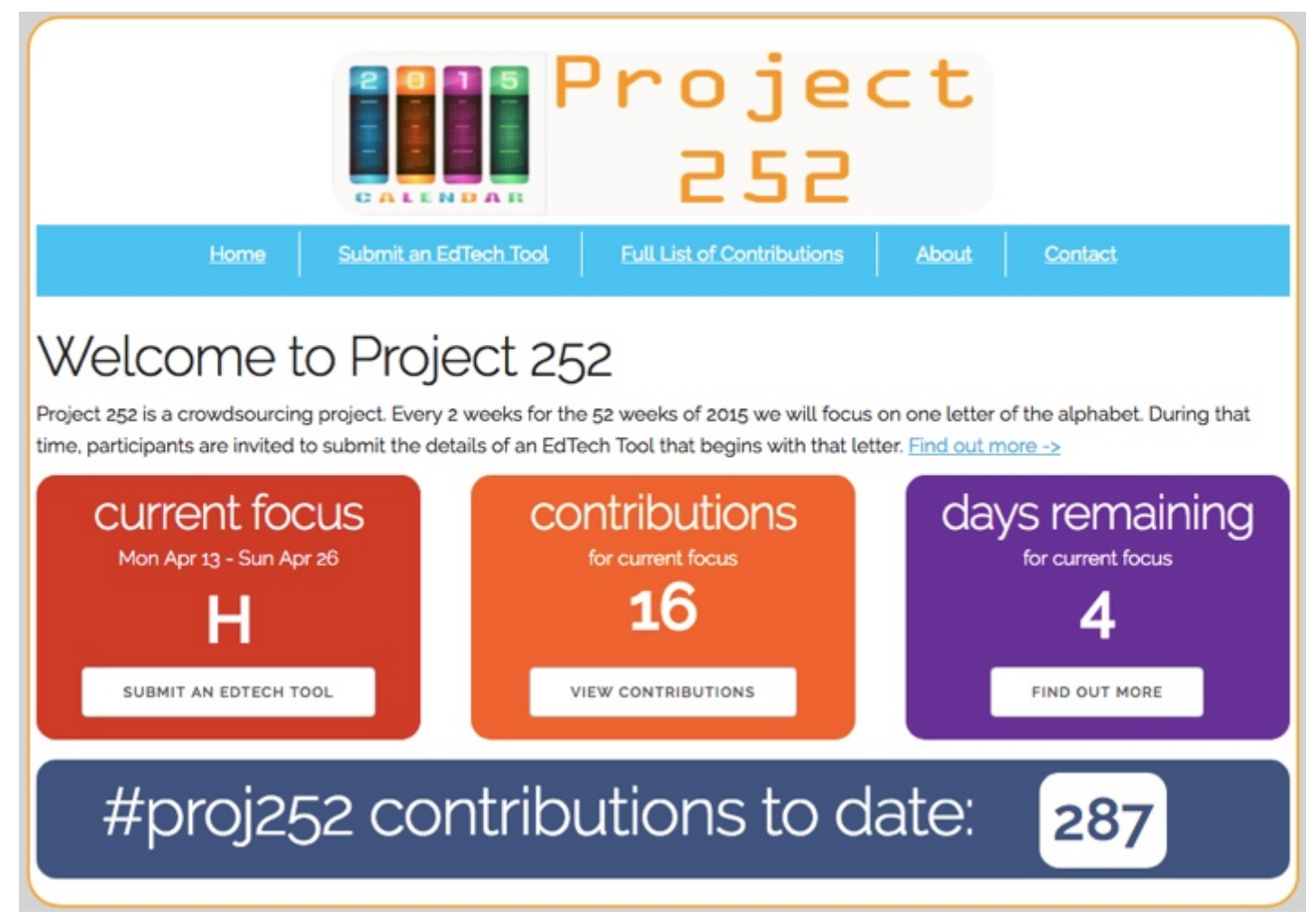

Figure 1. Project 252 home page (http://project252.donenda.com)

During the 2 weeks that a letter was live and the focus of contributions, it was advertised on the project website as the featured letter, and the call for contributions circulated via Twitter (further details below). Contributions were invited via a standard form which specified a number of criteria: the name of the tool, a URL to access, download or purchase it, a technical classification for the tool (online or specific to a particular operating system or device), suggested usage keywords for the tool, suggested uses for the tool in an educational setting, suggested academic subjects for its usage, pricing structure (free, free trial followed by purchase, once-off purchase, recurring cost), suggested educational level (primary, postprimary/secondary or higher education), suggested links to online tutorials or reviews for the tool, and an open comment field to enable contributors to add any information that they considered relevant (see Figure 2 for a partial illustration of the form used for this process). Contributors could choose to make a submission by logging into the site using their Twitter credentials (in order to associate their Twitter profile with their submission) or else anonymously (for those who did not wish to associate their Twitter account with their submission or did not have a Twitter account).
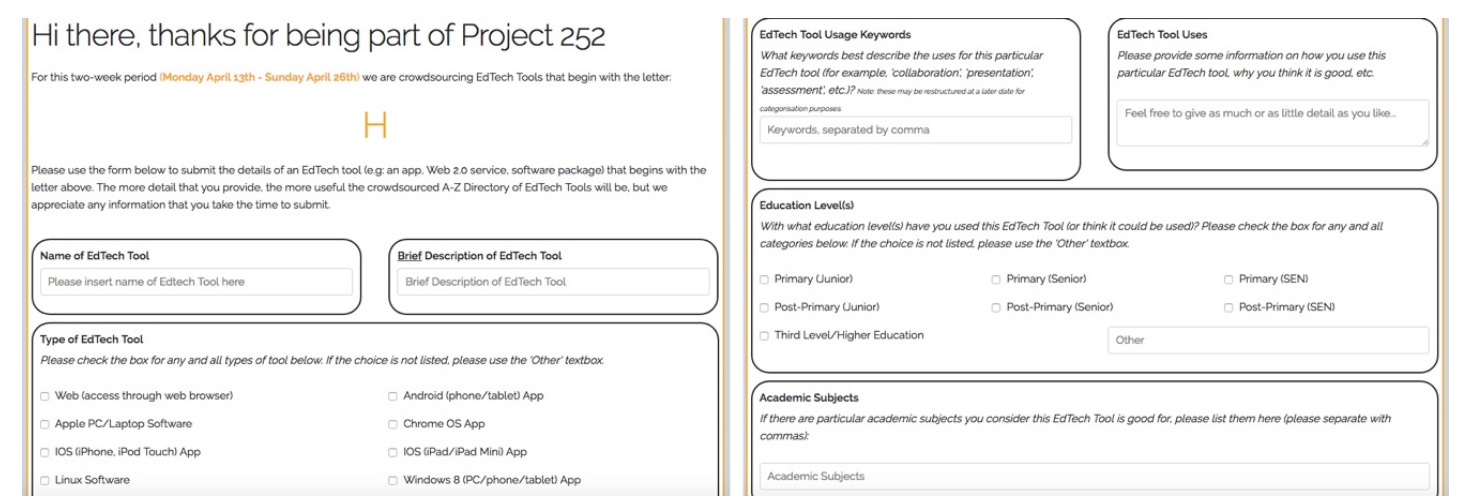

Figure 2. Project 252 contribution submission form (partial) 
Submissions were published on the project website within hours, following review by a project coordinator (the first author of this paper). This review was conducted to screen for inappropriate content and to ensure that the submitted entry related to teaching and learning; no judgement was applied regarding the authority of the contributor or the accuracy or quality of their submission. Figure 3 illustrates a sample Project 252 contribution.

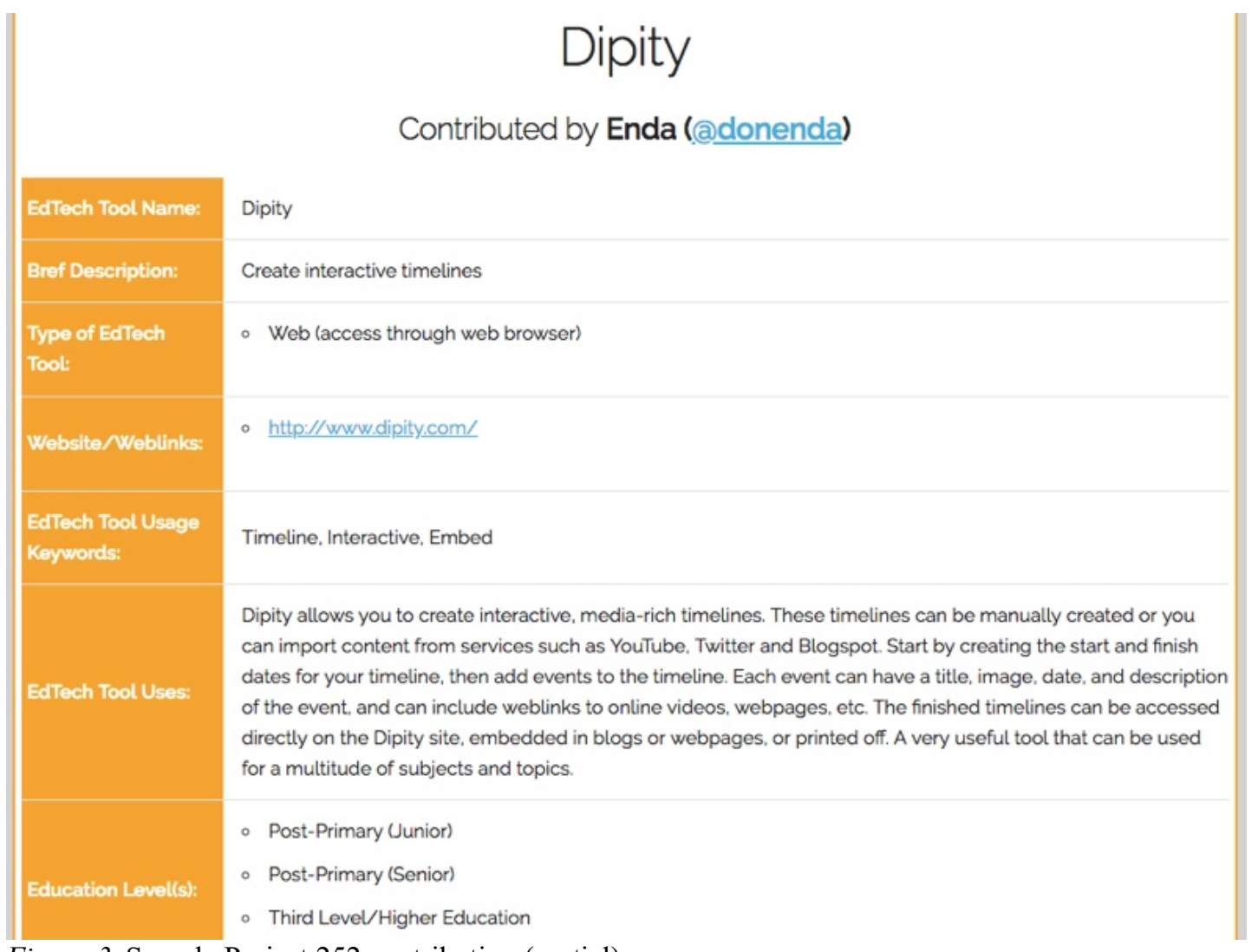

Figure 3. Sample Project 252 contribution (partial)

The project's Twitter account (@proj252) was used to announce each new featured letter window and the imminent closure of the current one, and to publicise each contribution as it was added to the directory. These tweets were also tagged with four educational hashtags to advertise them to educators on Twitter from a wide geographical spread (\#edchatie, \#edchat, \#ukedchat, \#aussieEd). Over 850 tweets were sent during the duration of the project, and the project's Twitter account accumulated over 150 followers across the year.

\section{Research design}

This paper presents a case study of the Project 252 crowdsourcing initiative. More specifically, Stake's (2005) categorisation of intrinsic case study was adopted as the case itself is of primary importance and the study was undertaken because of an intrinsic interest in it. Through in-depth description and analysis of this case (Merriam, 2009), the paper addresses the following research questions:

(1) What engagement occurred with this crowdsourcing initiative?

(2) What factors motivated people to contribute to the project?

In addressing these questions, the paper also reflects upon some of the wider insights that can be gained from the Project 252 experience, and how these may in turn contribute to ongoing discussions about the practices, potentials, and promises of crowdsourcing for purposes of teaching and learning.

Consistent with the case study methodology, data were collected from several sources. The first source was the Project 252 platform itself, which contained information such as data on the number of submissions for 
each letter, the categories chosen, and suggestions for use of the edtech tools. These data were extracted directly from the database powering the online platform and analysed using Excel. The second source was usage statistics for the site that were available through Google Analytics, which had been integrated on the project platform from its conception. Google Analytics has been shown to be a helpful tool for measuring the impact of online educational projects (Mc Guckin \& Crowley, 2012) and evaluating the process of Internet-delivered interventions (Crutzen, Roosjen, \& Poelman, 2013), and it provided rich geodemographic data and usage statistics for the current project. The online Google Analytics dashboard was used for filtering and analysis of this data.

Although this data provided much illumination with regard to the project itself, we were also anxious to garner opinions and experiences of participants who engaged in this crowdsourcing initiative, and thus ethical approval was secured in order to deploy a further data collection mechanism with a view to obtaining this feedback. A stratified sampling strategy was employed, which divided the user sample into three groups: those who contributed most submissions to the project (13 or more), those who contributed a smaller but significant number (between five and 12 contributions), and those who contributed least (four or fewer contributions). Ten participants were chosen by random selection from each strata and sent a link to an online survey (using Google Forms), which contained a number of open-ended questions designed to obtain qualitative responses about their experiences and opinions of partaking in the project. Online surveys have proven to be well suited to data gathering through their ability to reach a wide geographical area (particularly important for this project) and achieve quick returns, although their response rates are often low (Lefever, Dal, \& Matthíasdóttir, 2007). In all, 18 responses were received: eight from Group A (most contributions), seven from Group B (middle contributions), and three from Group C (least contributions). The survey was anonymous in nature, and participants did not supply any identifying information as part of their response. The survey responses were imported into NVivo, a well-established computer assisted qualitative data analysis software package for performing the analytical tasks of coding, retrieving, and annotating qualitative data (Schönfelder, 2011). Each response was read and coded initially with first cycle descriptive codes, which "[attribute] a class of phenomena to a segment of text" (Miles \& Huberman, 1994, p. 54) followed by a second cycle of coding through the use of pattern codes to "group together first cycle codes into a smaller number of sets, themes or constructs” (Miles \& Huberman, 1994, p. 69).

\section{Analysis and findings}

Analysis of the data is structured around the two central research questions outlined above: examining the levels and types of engagement with the crowdsourcing initiative and exploring the factors that motivated users to contribute.

\section{Engagement with crowdsourcing initiative}

The project received a total of 667 contributions by the time the crowdsourcing activity reached its conclusion in January 2016. These were compiled from a total of 96 named contributors who collectively contributed 640 entries, with a further 27 contributions submitted anonymously. The letter which received the most contributions is " $\mathrm{s}$ " with a total of 61 submissions, while the smallest number of contributions (n $=7$ ) was received for letter " $X$ ". There were 24 instances where a particular edtech tool was submitted more than once (from different contributors), with all other contributions $(n=626)$ being unique.

The most popular type of edtech tool submitted was online (in terms of technical classification) and free (in terms of pricing classification). Although the majority of submissions came from participants based in Ireland, contributions were also received from educators in the United Kingdom, Argentina, France, Belgium, Qatar, and the United States. A word-frequency analysis of contributions (expressed graphically in Figure 4) revealed the top three words to be "collaboration", "presentation", and "assessment" in terms of uses for the submitted edtech tools. 


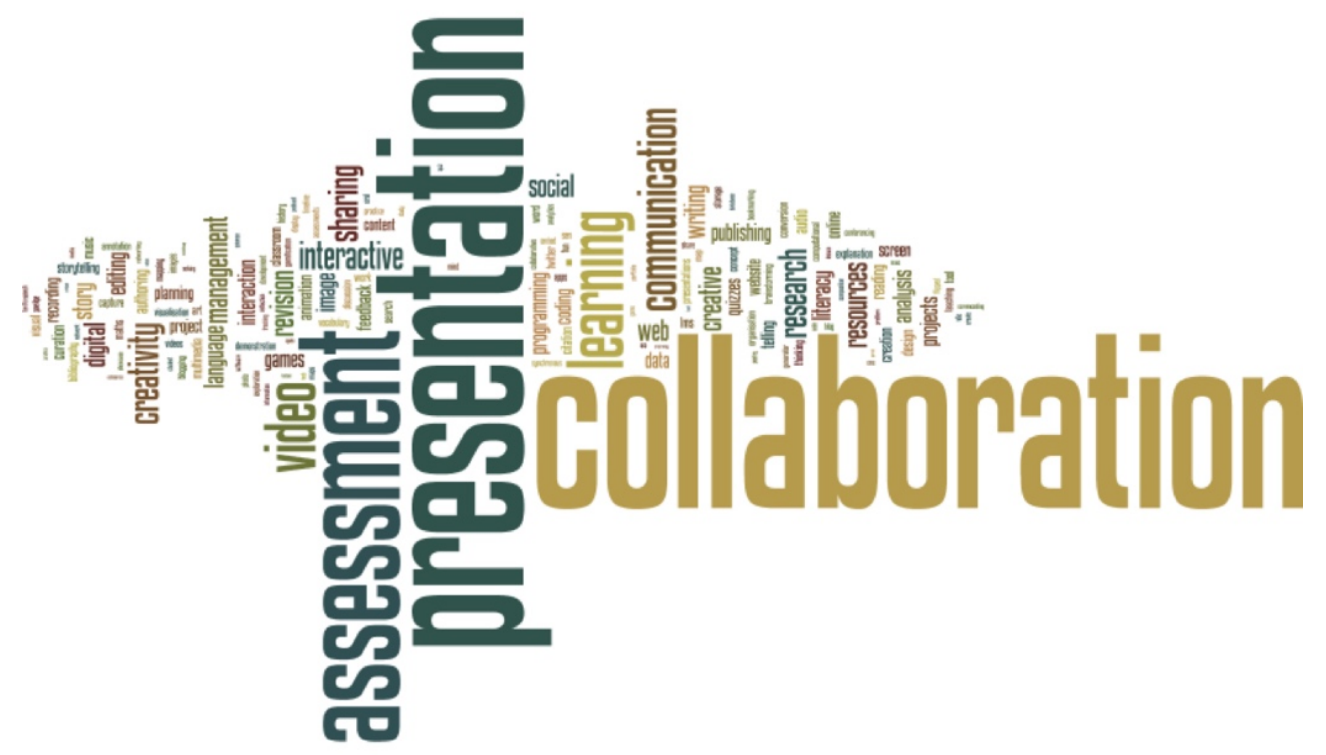

Figure 4. Word frequency analysis of crowdsourced contributions

The structure of the crowdsourced directory was positively described by one survey respondent as "lots of useful apps gathered in one tidy place" and by another as "a database of tools" with a "really nice layout". One respondent outlined the value of having "such a bank of resources 'all in one place' as hunting through the net can be so time consuming", while another compared it to an alternative approach for sourcing edtech tools:

Sometimes (eg through Twitter) 1 see great looking links/apps mentioned. I favourite them and then forget about them for a while! They then get swamped in a bank of favourites which becomes too vast to follow/find again. With Project 252, it's much easier to glance through the alphabetical list and either see something I intended to look at before, or be reminded of an app/tool I'd forgotten about.

The geographical spread of visitors to the project website is also notable in terms of engagement with the project: a review of Google Analytics data for the site reveals visitors from over 100 countries across five continents (see Figure 5).

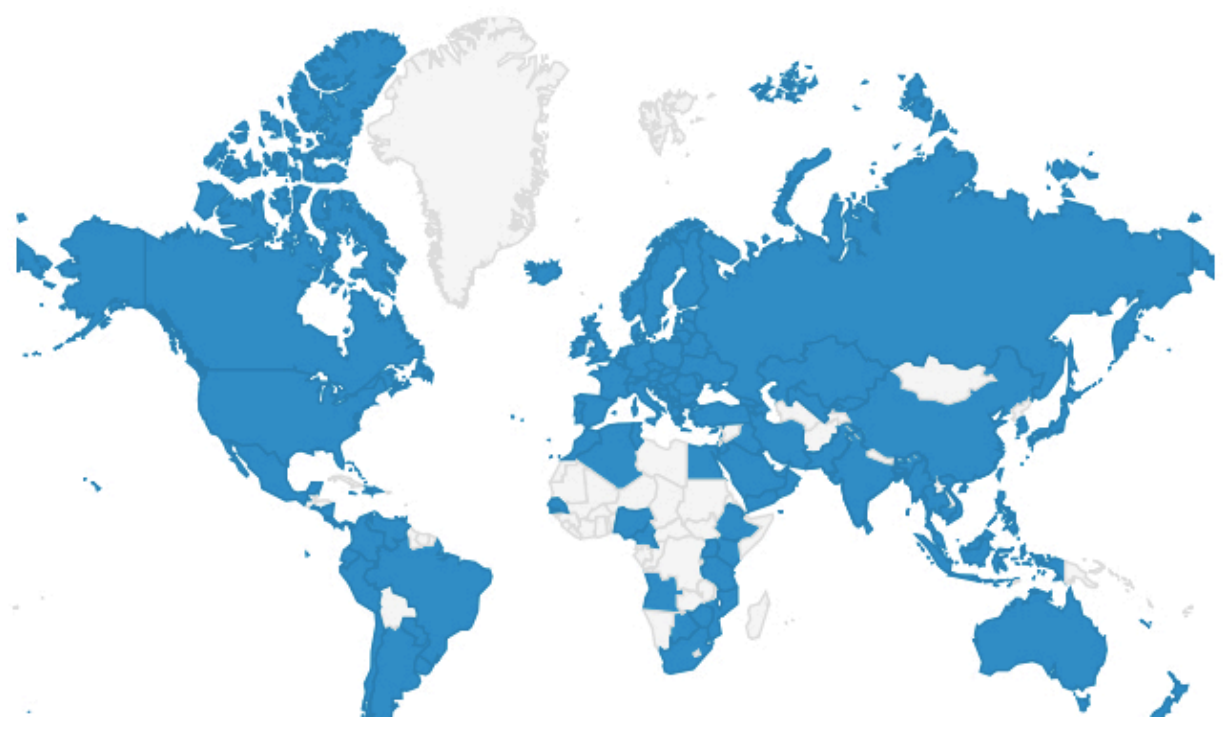

Figure 5. Geographical spread of visitors to Project 252 crowdsourced directory 
In addition, analysis of the access logs for the site reveals that engagement with the crowdsourced directory has remained steady even after the active crowdsourcing activity concluded. On the final day of crowdsourcing in January 2016, the directory of submissions had received almost 70,000 views, and this has grown to over 200,000 views in the 3 years following completion (see Figure 6).

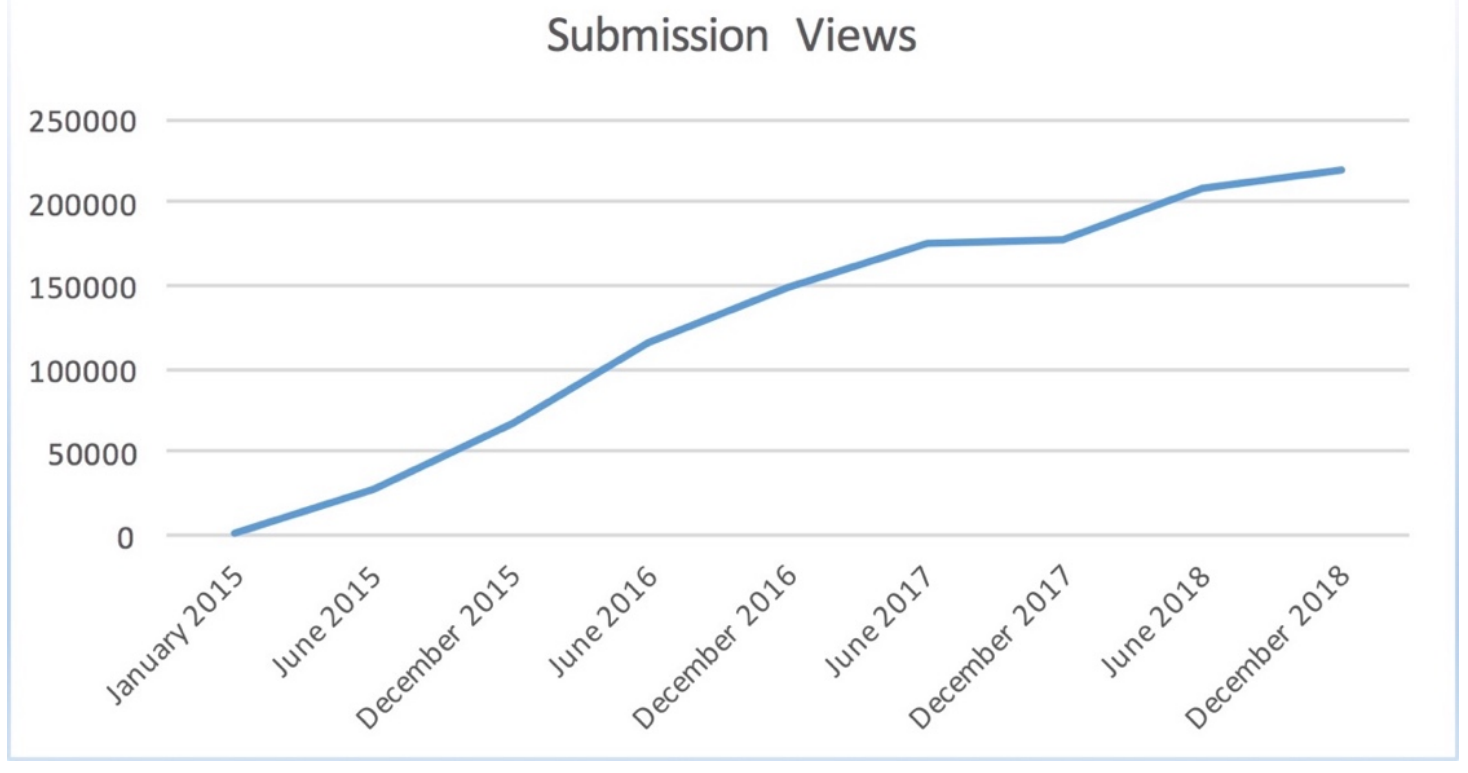

Figure 6. Views of Project 252 submissions

Responses to the online surveys indicated that users engaged with the crowdsourced directory in a number of educational ways that went beyond simply perusing the list of entries. For instance, one respondent outlined that they had set time aside each week to explore recent submissions as a form of "personal CPD [professional development]". Others indicated that they used the project as a basis for facilitating professional development workshops with staff: one respondent, for example, outlined that they "ask [staff] to pick a tool from the list and to discuss in groups how it might be used in their teaching", while another stated that they had "used it several times as a database for tools when supporting staff to choose solutions for teaching challenges". In addition, the vast majority of respondents indicated that they had employed tools that they had learned about from the crowdsourced directory as part of their own teaching and learning: "there were a few tools that I was introduced to through Project 252 and which I have continued to use in my teaching - this has had a big impact on my practice". Respondents also indicated that they had learned about the potential and power of crowdsourcing for educational purposes from engagement with the project, as illustrated through comments such as "I got a firsthand sense of how crowds can function to help solve problems for free!" and "I had no idea that crowdsourcing could be such an effective way of sharing knowledge before this".

Analysis of the contributions revealed that the section of the submission form that related to "suggested academic subjects for usage" of the submitted edtech tool received much less attention than other sections, with $369(55 \%)$ of the contributions not having any suggested academic subjects submitted at all and a further $84(12 \%)$ submitted with a broad classification such as "all", "all subjects", "any", "crossdiscipline", "transdiscipline", and "universal". A similar outcome was noted for the "suggested uses for the tool in an educational setting" field that contributors were invited to populate when submitting to the project, where considerable variation in the length of submission ranged from no comment at all (22 submissions) to contributions that exceeded 200 words (the average submission length was 48 words). It was notable, however, that the content submitted usually consisted of functional descriptions of what the tool broadly does (often conveying much the same information that had been submitted for the "brief description of the tool" field) rather than how the tool might be used educationally or in a pedagogical manner. The possible implications of this are discussed in the Discussion and conclusion section. Variation in the length of contributions was also noted with regard to the "brief description of tool" field, with submissions ranging from two words to 140 in length (the average was 11 words). 


\section{Motivating factors for contribution}

Our analysis of the multiple data sources resulted in a number of themes with regard to the factors that motivated people to participate in this project, and these are now explored.

\section{Format, competition and gamification}

The overall format and structure of the crowdsourcing project was one of the most-cited motivations for engaging in the crowdsourcing activity, with 12 of the 18 responses from the anonymous online survey highlighting this factor. It was clear that the fortnightly submission structure was predominantly well received by participants. One contributor, for instance, thought that "the format (a different letter every two weeks) was clever and intuitive and worked very well for the most part", while another reported that "the overall idea was great" and a third that they "kind of got hooked and wanted to contribute and share my knowledge of the tech tools that I like using".

Related to this, it emerged that a number of the participants perceived a competitive nature to the crowdsourcing activity that arose from the project structure. In several cases, this took the form of a personal challenge that contributors set for themselves. One participant, for example, explained that they "aimed to make a contribution to every letter" and "managed to contribute to most", while another commented that they "thought the format for the project was very clever and I set myself the challenge of trying to submit a Teaching/Learning tool for each of the letters". Analysis of the directory shows that only one user did, in fact, submit a contribution for each letter, with six users submitting for $70 \%$ or more of the letters. Other contributors, however, indicated that they considered making a submission to be much like a competitive race once a letter became live on the site, before someone else submitted that particular tool. In the words of one respondent, "I definitely felt an element of competition creeping in!", while another agreed that "there was a kind of a competitive element or something that kicked in as I guess you could get kudos for your expertise". One participant gave the following account of how they considered the competitive nature of the crowdsourcing task influenced their engagement with the project:

I became really determined to get my entry in before anybody else, I found myself checking the site early on Mondays to make sure I got in before somebody else did!

This is also evident in analysis of contributions, which revealed that that most popular days for submitting entries were Monday, the day that a new letter opened (with 148 contributions or $21.8 \%$ of the total) and Sunday, the day before a letter closed, thus suggesting that participants were anxious to submit their contribution before the deadline (with 153 contributions or $22.6 \%$ of the total).

It is notable that all but two of the 18 survey respondents indicated that they chose to not make a contribution to the site for an edtech tool that had already been submitted by someone else. For example, one participant outlined that "if someone else contributed the same app/tool, I usually spotted it and didn't contribute that one again", while another voiced that "I found that my contribution had already been submitted, that stopped me in my tracks". This is further supported by the analysis of submissions conducted above, which revealed that only 24 of the 667 contributions related to edtech tools that had more than one entry, with the vast majority (over 95\%) of contributions being unique. One participant proposed that this might be addressed with "a box for you to also add your endorsement and perhaps an additional comment", while another suggested that "a way of making a very quick but valuable contribution would be to rate an existing tool and/or comment on an existing entry".

\section{Collaboration and trust}

A further motivation that emerged for participation in the crowdsourcing activity was the desire to collaborate with other educators and to contribute to a community of educators. This was evident through such comments as "I have a very strong belief in the power of collaboration and sharing" and "sharing practice and ideas with others was my main reason for taking part". One participant specifically identified the crowdsourcing element of the project as a motivation for participating: "It only took a few minutes, but it could really benefit others, so the crowd-sourced, community element was very important to me". Several participants also indicated that they perceived a heightened level of trust to the crowdsourced directory because it was being compiled by educators who had experience of using the tool in question. One participant, for example, valued that "these tools/apps have been recommended, tried and tested by other educators" and considered that this "is literally a 21 st Century 'word of mouth' approach!", while others 
voiced that "knowing that these ideas were coming from other practising educators meant that I could trust the contributions" and that "the fact they were recommended by a discerning community of practitioners made it a valuable source". Related to this, the integration of contributors' Twitter identities into the project was cited as positive by several participants. For instance:

We were able to see the Twitter name of who made each contribution and I could then follow them on Twitter also (and many followed me back). I've learned a lot from some of those people after Project 252 finished.

Of the 18 survey respondents, 14 also outlined that they had recommended the crowdsourced directory to other people, including "student teachers", "educators", "practicing teachers", "students", "staff", "colleagues", and "workshop participants". This sharing occurred mainly through social media channels, professional development workshops, lectures, and tutorials. This continued sharing and recommendation of the crowdsourced directory is further evidenced (and is likely a strong factor) in the ongoing usage of the directory of EdTech tools since its completed compilation (see Figures 5 and 6, above).

Respondents also highlighted the cross-sectoral dimension of the project as a positive reason for engagement with the crowdsourced directory; for instance, "it was also useful that educators across all sectors contributed so teachers learned about resources that teachers in other sectors were already using and familiar with", and "it was really interesting to see how other educators at different levels of the system use the same tools that we do, I picked up some great ideas from some of these". An analysis of named contributors (via their associated Twitter profiles) confirmed an appreciable spread of submissions from across the education spectrum. For example, the top 10 contributors comprised three teachers from the primary sector, two post-primary/secondary teachers, and five from the higher education sector. This crosssectoral range is also reflected in the classification of edtech tools submitted: 401 of the 667 submissions were suggested by the initial contributor during the crowdsourcing process to be suitable for senior primary pupils, 483 as relevant for senior post-primary/secondary pupils, and 481 for higher education students.

\section{Discussion and conclusion}

This paper has presented an intrinsic case study of a year-long crowdsourcing initiative to compile a directory of edtech tools for teaching and learning. In doing so it has sought to address two research questions. The first of these asked what engagement occurred with this crowdsourcing initiative. We found that participants from across the spectrum of educational sectors contributed to this project from a range of geographical locations, with significantly greater numbers engaging with the directory that resulted from the crowdsourcing activity. In all, 677 unique contributions were made by 96 named contributors (and with 27 contributions made by anonymous contributors). Visitors from over 100 countries across five continents have accessed the crowdsourced directory over 200,000 times in the 3 years following completion. This case study therefore provides further evidence of the value of the open call with regard to sourcing a diverse range of contributions, and from a wide geographical base (Paulin \& Haythornthwaite, 2016), and the effectiveness of web-based technologies for crowdsourcing purposes (Saxton et al., 2013). We also found that participants engaged with the crowdsourced directory in a number of educational ways that included "personal CPD", use of the directory to facilitate professional development workshops with staff, and use of tools that they had learned about from the crowdsourced directory within their own teaching and learning. In this regard our study also contributes to emerging discussions about the use of crowdsourcing techniques and resources for purposes of continuing professional development (Scott, 2015). A further note of significance was that the most popular type of edtech tool submitted was "online" (in terms of technical classification) and "free" (in terms of pricing classification) - a particularly positive outcome when considering the open nature of the project in terms of design, collation and dissemination of contributions, and in the light of growing tendencies within education towards openness (Weller, 2014).

The second research question considered the factors that motivated people to contribute to the project. We found that motivations included a sense of competition (both with self and others) that arose from the structure and methodology employed, the desire to collaborate with other educators from across educational sectors, and the perception that the crowdsourcing activity gave rise to a trustworthy resource. In this regard, our study further illustrates how crowdsourcing can bring together communities of interest and concern (Paulin \& Haythornthwaite, 2016). It also contributes to a growing body of literature illustrating how crowdsourcing can fulfil the old adage that the whole is often greater than the sum of its parts (Pionke, 
2013) and on the motivational factors that underpin participants' engagement with crowdsourcing (Feng, Ye, Yu, Yang, \& Cui, 2018; Zhao \& Zhu, 2014).

A number of insights can be gained from the Project 252 experience. The first of these relates to the potential of the crowdsourcing methodology formulated for this project, which encompasses elements of collaboration, competition, and gamification. This emerged as one of the primary drivers for contributors to engage in the crowdsourcing activity in encouraging participants to suggest tools early in the 2-week window to be the first to do so. It is possible that the positive response to these elements within the crowdsourcing strategy for the current project is related to their growing significance with regard to education in the broader sense. For instance, the use of online platforms for collaboration among teachers with a view to informal learning (Ab Rashid, Yahaya, Rahman, \& Yunus, 2016) and the sharing of resources (Ranieri, Manca, \& Fini, 2012) has been well established, particularly with regard to Twitter (e.g., McPherson, Budge, \& Lemon, 2015), which played an important role in circulating the crowdsourcing call throughout the project and in disseminating the contributions as they were submitted. Likewise, gamification has become a focus of much attention for education in recent times (Dicheva, Dichev, Agre, \& Angelova, 2015), particularly with regard to motivation and engagement factors associated with the use of game-based strategies in teaching and learning (van Roy \& Zaman, 2018). These issues of competition and gamification have also been of interest with regard to crowdsourcing (Feng et al., 2018). Morschheuser, Hamari, Koivisto, and Maedche (2017), for instance, proposed that crowdsourcing platforms are increasingly imbued with motivational design features borrowed from games (gamification) due to crowdsourcing's success requiring a body of motivated crowdsourcees, and that we are witnessing the emergence of an "interwoven phenomena of gamification and crowdsourcing" (p. 38). Dunn and Hedges (2013) noted that competition featured strongly as a factor for a number of interviewees in their study of crowdsourcing, but proposed that "super contributors" (p. 154) are the ones most likely to feel competitive towards the crowdsourcing task. This observation is consistent with the findings from our study, where the majority of comments referring to competition were from the highest contributing strata of participants. Less clear, however, is whether the gamification of this crowdsourcing project ultimately resulted in a greater number of submissions to the crowdsourced directory (through an increased engagement as a result of the competitive dimension) or a lesser one (through participants' disinclination to submit duplicate entries). The unwillingness of participants to submit a tool to the directory that had already been committed by someone else was not an intended outcome of the project; indeed, it was hoped that participants would submit several accounts of the same edtech tool, which could be linked to heighten the quality of the overall information available for that tool (particularly in terms of its various educational and pedagogical uses) but this occurred in only a small number of instances.

This brings us to a second and related issue for further discussion: the analysis of the "suggested academic subjects for usage" and "suggested uses for the tool in an educational setting" fields. The comparatively undeveloped inputs for these fields give rise to a potentially techno-determinist (the assumption that integrating technology into the learning process is by its very nature positive or desirable - Steffens et al., 2015) or techno-centric (learning about the tool or technology or the effects of the tool or technology itself, rather than learning with or through the technology - Brennan, 2015) dimension of the project. Of course, these issues have long standing within debates on the use of technology in education (e.g., Papert, 1987; Salomon, 2016). On the other hand, the fewer contributions for these fields may simply be a result of these sections occurring towards the end of the overall submission form and therefore receiving less attention, and thus further investigation is required to clarify this interpretation. A concern about potential technocentrism also gives rise to considerations to the overall quality of the crowdsourced entries, a factor that has been considered elsewhere with regard to crowdsourcing for educational purposes (Blackwell et al., 2016). Although no measurement of quality was applied to the entries during the crowdsourcing activity or analysis for this paper, variety in length of submissions was noted.

A number of recommendations and suggestions for further research emerge from our study. The first arises from acknowledging that this intrinsic case study is based on one individual crowdsourcing project and thus the findings cannot be considered generalisable, although we are hopeful that the level of detail provided will contribute towards transferability (Merriam, 2009) in this regard. Related to this, the project structure, as well as the crowdsourcing methodology driven by elements of collaboration, competition and gamification, has been sufficiently outlined and illustrated so that a similar approach might be utilised by other researchers interested in adopting or adapting this crowdsourcing model. While this particular case study saw this methodology employed to crowdsource an A-Z directory of edtech tools, the crowdsourcing 
methodology could, in theory, be used to compile a list or directory for any topic or subject. A second recommendation would be to expand the gamified nature of the crowdsourcing methodology, in light of the fact that competition and gamification were clearly factors in the current project; Morschheuser et al. (2017) outlined a number of gamification strategies that can be integrated with a crowdsourcing approach and which might be considered in this regard. Related to this point is the suggestion that arose from the qualitative survey responses to allow participants to rate and/or comment on an existing entry, which could potentially help to address a number of issues outlined above, including the unwillingness of participants to submit to the directory if they see that their intended contribution has already been published. Moreover, this might help to address some of the potentially techno-determinist and techno-centric concerns with regard to pedagogical uses of the edtech tools and may also serve to enhance the overall quality of the entries in the directory. A further recommendation is to apply a Wikipedia-like approach to the crowdsourced entries, which would see the option for cross-linkage between submissions and the ability for more than one person to contribute to an entry. The value of such functionality to Wikipedia is well established (e.g., Anthony, Smith, \& Williamson, 2009) and would likely be a valuable development for our project, which would see standalone and separate records transformed into interrelated entries, thereby bringing greater coherence and improved fluidity to the overall directory. A final recommendation is to give further consideration to the use of the term tool as employed during this project, as it is a contested term regarding perceptions of neutrality when used to discuss digital technologies (e.g., Hall, 2011; Selwyn, 2016).

Notwithstanding these limitations and suggestions for further investigation, we conclude that the example of Project 252 illustrates the power of the crowd for collaboration, contribution, and collation for educational purposes. When combined with a novel crowdsourcing methodology that encompasses competition and gamification, the experience provides a valuable case study with insightful lessons for considering the wider potential of crowdsourcing for teaching and learning.

\section{References}

Ab Rashid, R., Yahaya, M. F., Rahman, M. F. A., \& Yunus, K. (2016). Teachers’ informal learning via social networking technology. International Journal of Emerging Technologies in Learning, 11(10), 76-79. https://doi.org/10.3991/ijet.v11i10.5908

Aitamurto, T., Landemore, H., \& Saldivar Galli, J. (2017). Unmasking the crowd: Participants' motivation factors, expectations, and profile in a crowdsourced law reform. Information, Communication and Society, 20(8), 1239-1260. https://doi.org/10.1080/1369118X.2016.1228993

Al-Jumeily, D., Hussain, A., Alghamdi, M., Dobbins, C., \& Lunn, J. (2015). Educational crowdsourcing to support the learning of computer programming. Research and Practice in Technology Enhanced Learning, 10(1), 13. https://doi.org/10.1186/s41039-015-0011-3

Anthony, D., Smith, S. W., \& Williamson, T. (2009). Reputation and reliability in collective goods: The case of the online encyclopaedia Wikipedia. Rationality and Society, 21(3), 283-306. https://doi.org/10.1177/1043463109336804

Armstrong, A. W., Cheeney, S., Wu, J., Harskamp, C. T., \& Schupp, C. W. (2012). Harnessing the power of crowds: Crowdsourcing as a novel research method for evaluation of acne treatments. American Journal of Clinical Dermatology, 13(6), 405-416. https://doi.org/10.2165/11634040-000000000$\underline{00000}$

Blackwell, K. A., Travis, M. J., Arbuckle, M. R., \& Ross, D. A. (2016). Crowdsourcing medical education. Medical Education, 50(5), 576. https://doi.org/10.1111/medu.13010

Bow, H., Dattilo, J., Jonas, A., \& Lehmann, C. (2013). A crowdsourcing model for creating preclinical medical education study tools. Academic Medicine, 88(6), 766-770. https://doi.org/10.1097/ACM.0b013e31828f86ef

Brabham, D. C. (2010). Moving the crowd at Threadless. Information, Communication and Society, 13(8), 1122-1145. https://doi.org/10.1080/13691181003624090

Brennan, K. (2015). Beyond technocentrism: Supporting constructionism in the classroom. Constructivist Foundations, 10(3), 289-296. Retrieved from http://constructivist.info/10/3/289

Chan, T., Thoma, B., \& Lin, M. (2015). Creating, curating, and sharing online faculty development resources: The Medical Education in Cases series experience. Academic Medicine, 90(6), 785-789. https://doi.org/10.1097/ACM.0000000000000692 
Crutzen, R., Roosjen, J. L., \& Poelman, J. (2013). Using Google Analytics as a process evaluation method for internet-delivered interventions: An example on sexual health. Health Promotion International, 28(1), 36-42. https://doi.org/10.1093/heapro/das008

Dicheva, D., Dichev, C., Agre, G., \& Angelova, G. (2015). Gamification in education: A systematic mapping study. Journal of Educational Technology \& Society, 18(3), 75-88. Retrieved from http://www.jstor.org/stable/jeductechsoci.18.3.75

Donlon, E., Brown, M., \& Costello, E. (2016). The power of the crowd: Promise and potential of crowdsourcing for education. In S. Barker, S. Dawson, A. Pardo, \& C. Colvin (Eds.), Show Me the Learning: Proceedings of the ASCILITE 2016 Conference (pp. 206-211). Retrieved from http://2016conference.ascilite.org/wp-content/uploads/ascilite2016 donlon concise.pdf

Dunn, S., \& Hedges, M. (2013). Crowd-sourcing as a component of humanities research infrastructures. International Journal of Humanities and Arts Computing, 7(1-2), 147-169. https://doi.org/10.3366/ijhac.2013.0086

Estellés-Arolas, E., \& González-Ladrón-de-Guevara, F. (2012). Towards an integrated crowdsourcing definition. Journal of Information Science, 38(2), 189-200. https://doi.org/10.1177/0165551512437638

Feng, Y., Ye, H. J., Yu, Y., Yang, C., \& Cui, T. (2018). Gamification artifacts and crowdsourcing participation: Examining the mediating role of intrinsic motivations. Computers in Human Behavior, 81, 124-136. https://doi.org/10.1016/j.chb.2017.12.018

Foroughi, A. (2015). The theory of connectivism: Can it explain and guide learning in the digital age? Journal of Higher Education Theory and Practice, 15(5), 11-26. Retrieved from http://t.www.nabusinesspress.com/JHETP/ForoughiA_Web15 5 .pdf

Foulger, T. S. (2014). The 21 st-century teacher educator and crowdsourcing. Journal of Digital Learning in Teacher Education, 30(4), 110. https://doi.org/10.1080/21532974.2014.927205

Hall, R. (2011). Revealing the transformatory moment of learning technology: The place of critical social theory. Research in Learning Technology, 19(3), 273-284. https://doi.org/10.1080/21567069.2011.624996

Hills, T. T. (2015). Crowdsourcing content creation in the classroom. Journal of Computing in Higher Education, 27(1), 47-67. https://doi.org/10.1007/s12528-015-9089-2

Hossain, M., \& Kauranen, I. (2015). Crowdsourcing: A comprehensive literature review. Strategic Outsourcing: An International Journal, 8(1), 2-22. https://doi.org/10.1108/SO-12-2014-0029

Howe, J. (2006). Crowdsourcing: A definition. Retrieved 15 July, 2016, from http://crowdsourcing.typepad.com/cs/2006/06/crowdsourcing a.html

Jhangiani, R. S., Green, A. G., \& Belshaw, J. D. (2016). Three approaches to open textbook development. In P. Blessinger \& T. J. Bliss (Eds.), Open education: International perspectives in higher education (pp. 179-198). https://doi.org/10.11647/OBP.0103.09

Karataev, E., \& Zadorozhny, V. (2017). Adaptive social learning based on crowdsourcing. IEEE Transactions on Learning Technologies, 10(2), 128-139. https://doi.org/10.1109/TLT.2016.2515097

Lefever, S., Dal, M., \& Matthíasdóttir, Á. (2007). Online data collection in academic research: Advantages and limitations. British Journal of Educational Technology, 38(4), 574-582. https://doi.org/10.1111/j.1467-8535.2006.00638.x

Mc Guckin, C., \& Crowley, N. (2012). Using Google Analytics to evaluate the impact of the CyberTraining project. Cyberpsychology, Behavior and Social Networking, 15(11), 625-629. https://doi.org/10.1089/cyber.2011.0460

McPherson, M., Budge, K., \& Lemon, N. (2015). New practices in doing academic development: Twitter as an informal learning space. International Journal for Academic Development, 20(2), 126-136. https://doi.org/10.1080/1360144X.2015.1029485

Merriam, S. B. (2009). Qualitative research: A guide to design and implementation. San Francisco, CA: Jossey-Bass.

Miles, M. B., \& Huberman, A. M. (1994). Qualitative data analysis (2nd ed.). London, United Kingdom: Sage.

Morschheuser, B., Hamari, J., Koivisto, J., \& Maedche, A. (2017). Gamified crowdsourcing: Conceptualization, literature review, and future agenda. International Journal of Human-Computer Studies, 106, 26-43. https://doi.org/10.1016/j.ijhcs.2017.04.005

Mustafa, E., \& Mohd Adnan, H. (2017). Crowdsourcing: A platform for crowd engagement in the publishing industry. Publishing Research Quarterly, 33(3), 283-296. https://doi.org/10.1007/s12109$\underline{017-9525-4}$ 
Orozco, D. (2016). The use of legal crowdsourcing ("Lawsourcing") to achieve legal, regulatory, and policy objectives. American Business Law Journal, 53(1), 145-192. https://doi.org/10.1111/ablj.12074

O'Shea, P., \& Kidd, J. (2011). Crowdsourced grading: Exploring the validity and effects of studentauthored and student-evaluated textbooks. In S. Barton, J. Hedberg, \& K. Suzuki (Eds.), Proceedings of Global Learn Asia Pacific 2011 - Global Conference on Learning and Technology (pp. 12661271). Waynesville, NC: Association for the Advancement of Computing in Education. Retrieved from https://www.learntechlib.org/p/37329/

Papert, S. (1987). Information technology and education: Computer criticism vs. technocentric thinking. Educational Researcher, 16(1), 22-30. https://doi.org/10.3102/0013189X016001022

Paulin, D., \& Haythornthwaite, C. (2016). Crowdsourcing the curriculum: Redefining e-learning practices through peer-generated approaches. The Information Society, 32(2), 130-142. https://doi.org/10.1080/01972243.2016.1130501

Pionke, A. D. (2013). A pedagogical experiment in crowdsourcing and enumerative bibliography. Journal on Excellence in College Teaching, 24(1), 5-22. Retrieved from https://www.learntechlib.org/p/132558/

Porcello, D., \& Hsi, S. (2013). Crowdsourcing and curating online education resources. Science, 341(6143), 240-241. https://doi.org/10.1126/science.1234722

Ranieri, M., Manca, S., \& Fini, A. (2012). Why (and how) do teachers engage in social networks? An exploratory study of professional use of Facebook and its implications for lifelong learning. British Journal of Educational Technology, 43(5), 754-769. https://doi.org/10.1111/j.14678535.2012.01356.x

Salomon, G. (2016). It's not just the tool but the educational rationale that counts. In E. Elstad (Ed.), Educational technology and polycontextual bridging (pp. 149-161). Rotterdam, The Netherlands: Sense.

Saxton, G. D., Oh, O., \& Kishore, R. (2013). Rules of crowdsourcing: Models, issues, and systems of control. Information Systems Management, 30(1), 2-20. https://doi.org/10.1080/10580530.2013.739883

Schönfelder, W. (2011). CAQDAS and qualitative syllogism logic - NVivo 8 and MAXQDA 10 compared. Forum: Qualitative Social Research, 12(1), Art 21. https://doi.org/10.17169/fqs-12.1.1514

Scott, C. (2015). Designing mathematics instruction utilizing crowdsourcing as a professional development model. Journal of Higher Education Theory \& Practice, 15(2), 11-18. Retrieved from http://digitalcommons.www.na-businesspress.com/JHETP/ScottC Web15_2_.pdf

Selwyn, N. (2016). Education and technology: Key issues and debates. London, United Kingdom: Bloomsbury Publishing.

Skaržauskaitè, M. (2012). The application of crowd sourcing in educational activities. Social Technologies, 2(1), 67-76. Retrieved from https:/www3.mruni.eu/ojs/socialtechnologies/article/view/145/0

Solemon, B., Ariffin, I., Din, M. M., \& Anwar, R. M. (2013). A review of the uses of crowdsourcing in higher education. International Journal of Asian Social Science, 3(9), 2066-2073. Retrieved from http://www.aessweb.com/journals/September2013/5007/2409

Stake, R. E. (2005). Qualitative case studies. In N. K. Denzin \& Y. Lincoln (Eds.), Handbook of qualitative research (2nd ed., pp. 443-466). London, United Kingdom: Sage.

Steffens, K., Bannan, B., Dalgarno, B., Bartolomé, A. R., Esteve-González, V., \& Cela-Ranilla, J. M. (2015). Recent developments in technology-enhanced learning: A critical assessment. International Journal of Educational Technology in Higher Education, 12(2), 73-86. https://doi.org/10.7238/rusc.v12i2.2453

Tarasowa, D., Khalili, A., \& Auer, S. (2015). CrowdLearn: Crowd-sourcing the creation of highlystructured e-learning content. International Journal of Engineering Pedagogy, 5(4), 47-54. https://doi.org/10.3991/ijep.v5i4.4951

van Haren, R. (2017). Crowdsourcing feedback. Literacy Learning: The Middle Years, 25(1), 7-15. Retrieved from https://www.alea.edu.au/documents/item/1468

van Roy, R., \& Zaman, B. (2018). Need-supporting gamification in education: An assessment of motivational effects over time. Computers \& Education, 127, 283-297. https://doi.org/10.1016/j.compedu.2018.08.018

Weller, M. (2011). The digital scholar: How technology is transforming scholarly practice. London, United Kingdom: Bloomsbury. 
Weller, M. (2014). The battle for open: How openness won and why it doesn't feel like victory. London, United Kingdom: Ubiquity Press.

White-Farnham, J., \& Caffrey Gardner, C. (2014). Crowdsourcing the curriculum: Information literacy instruction in first-year writing. Reference Services Review, 42(2), 277-292. https://doi.org/10.1108/RSR-09-2013-0046

Zahirović Suhonjić, A., Despotović-Zrakić, M., Labus, A., Bogdanović, Z., \& Barać, D. (2019). Fostering students' participation in creating educational content through crowdsourcing. Interactive Learning Environments, 27(1), 72-85. https://doi.org/10.1080/10494820.2018.1451898

Zhao, Y. C., \& Zhu, Q. (2014). Effects of extrinsic and intrinsic motivation on participation in crowdsourcing contest. Online Information Review, 38(7), 896-917. https://doi.org/10.1108/OIR-082014-0188

Zhou, Q, Sun, H, Zhou, R, Sun, G, Shen, J, Li, K-C. (2018). A collaborative and open solution for largescale online learning. Computer Applications in Engineering Education, 26(6), 2266-2281. https://doi.org/10.1002/cae.22040

Corresponding author: Enda Donlon, enda.donlon@dcu.ie

Copyright: Articles published in the Australasian Journal of Educational Technology (AJET) are available under Creative Commons Attribution Non-Commercial No Derivatives Licence (CC BY-NC-ND 4.0). Authors retain copyright in their work and grant AJET right of first publication under CC BY-NC-ND 4.0.

Please cite as: Donlon, E., Costello, E., \& Brown, M. (2020). Collaboration, collation, and competition: Crowdsourcing a directory of educational technology tools for teaching and learning. Australasian Journal of Educational Technology, 36(3), 41-55. https://doi.org/10.14742/ajet.5712 